\title{
Correlation between interface energetics and open circuit voltage in organic photovoltaic cells
}

Cite as: Appl. Phys. Lett. 101, 233301 (2012); https://doi.org/10.1063/1.4769360

Submitted: 10 October 2012 . Accepted: 15 November 2012 . Published Online: 04 December 2012

A. Wilke, J. Endres, U. Hörmann, J. Niederhausen, R. Schlesinger, J. Frisch, P. Amsalem, J. Wagner, M. Gruber, A. Opitz, A. Vollmer, W. Brütting, A. Kahn, and N. Koch
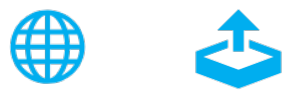

\section{ARTICLES YOU MAY BE INTERESTED IN}

Two-layer organic photovoltaic cell

Applied Physics Letters 48, 183 (1986); https://doi.org/10.1063/1.96937

Light intensity dependence of open-circuit voltage of polymer:fullerene solar cells

Applied Physics Letters 86, 123509 (2005); https://doi.org/10.1063/1.1889240

Detailed Balance Limit of Efficiency of p-n Junction Solar Cells

Journal of Applied Physics 32, 510 (1961); https://doi.org/10.1063/1.1736034

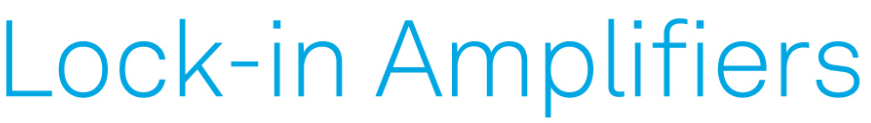

... and more, from DC to $600 \mathrm{MHz}$

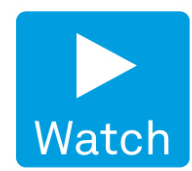




\title{
Correlation between interface energetics and open circuit voltage in organic photovoltaic cells
}

\author{
A. Wilke, ${ }^{1}$ J. Endres ${ }^{2}$ U. Hörmann, ${ }^{3}$ J. Niederhausen, ${ }^{1}$ R. Schlesinger,${ }^{1}$ J. Frisch, ${ }^{1}$ \\ P. Amsalem, ${ }^{1}$ J. Wagner, ${ }^{3}$ M. Gruber,${ }^{3}$ A. Opitz, ${ }^{1}$ A. Vollmer, ${ }^{4}$ W. Brütting, ${ }^{3}$ A. Kahn, ${ }^{2}$ \\ and N. Koch ${ }^{1,4}$ \\ ${ }_{1}^{1}$ Institut für Physik, Humboldt-Universität zu Berlin, Brook-Taylor-Str. 15, D-12489 Berlin, Germany \\ ${ }^{2}$ Department of Electrical Engineering, Princeton University, Princeton, New Jersey 08544, USA \\ ${ }^{3}$ Institut für Physik, Universität Augsburg, Universitätsstr. 1, D-86135 Berlin, Germany \\ ${ }^{4}$ Helmholtz-Zentrum Berlin für Materialien und Energie GmbH-BESSY II, \\ Albert-Einstein-Str. 15, D-12489 Berlin, Germany
}

(Received 10 October 2012; accepted 15 November 2012; published online 4 December 2012)

\begin{abstract}
We have used ultraviolet and inverse photoemission spectroscopy to determine the transport gaps $\left(\mathrm{E}_{\mathrm{t}}\right)$ of $\mathrm{C}_{60}$ and diindenoperylene (DIP), and the photovoltaic gap $\left(E_{P V G}\right)$ of five prototypical donor/ acceptor interfaces used in organic photovoltaic cells (OPVCs). The transport gap of $\mathrm{C}_{60}$ $(2.5 \pm 0.1) \mathrm{eV}$ and DIP $(2.55 \pm 0.1) \mathrm{eV}$ at the interface is the same as in pristine films. We find nearly the same energy loss of ca $0.5 \mathrm{eV}$ for all material pairs when comparing the open circuit voltage measured for corresponding OPVCs and $E_{P V G}$. (C) 2012 American Institute of Physics. [http://dx.doi.org/10.1063/1.4769360]
\end{abstract}

The energy level alignment at the donor/acceptor (D/A) heterojunction of an organic photovoltaic cell (OPVC) is decisive for its performance. In particular, the energy offset between the lowest unoccupied molecular orbital level of the acceptor [LUMO(A)] and the highest occupied molecular orbital level of the donor [HOMO(D)] sets an upper limit for the open circuit voltage $V_{o c}{ }^{1-6}$ This has been expressed as $e \cdot V_{o c}=\mathrm{HOMO}(\mathrm{D})-\mathrm{LUMO}(\mathrm{A})-\Delta$, where $e$ is the elementary charge and $\Delta$ a loss term, which has been suggested to be related to the exciton binding energy ${ }^{2}$ or radiative and nonradiative temperature dependent losses. ${ }^{1,3,5}$ The $\operatorname{HOMO}(\mathrm{D}) /$ LUMO(A) offset is denoted in various ways in the literature, such as charge transfer gap, intermolecular gap, or donor/ acceptor gap and is often estimated by optical spectroscopy, 5,6 or electrical characterization, e.g., cyclic voltammetry, ${ }^{6}$ reverse saturation current analysis, ${ }^{2,7}$ or temperature dependent measurements of the open circuit voltage. ${ }^{4,5}$ To avoid ambiguity, we use the term photovoltaic gap $\left(E_{P V G}\right)$ (cf Fig. 1). To minimize energy losses during the photon harvesting process, it is desirable to maximize $E_{P V G}$ within the constraint of keeping the LUMO-LUMO $\left(\Delta E_{\mathrm{L}}\right)$ and HOMO-HOMO level offsets $\left(\Delta E_{\mathrm{H}}\right)$ sufficiently large to drive charge separation across the D/A junction. To quantify $\Delta$ for unraveling its physical origin, it is mandatory to have reliable $E_{P V G}$ values for comparison with corresponding $V_{o c}$ values. Unfortunately, simple models for estimating the energy levels at organicorganic interfaces are often invalid (e.g., vacuum level alignment ${ }^{8,9}$ ), and more involved models have been brought forward. ${ }^{10,11}$ For the time being, experimental determination of interface energetics is indispensable to understand the processes inside an OPVC based on reliable values of $E_{P V G}$, but only few pertinent studies have been conducted to date. ${ }^{12-15}$

The present study focuses on $E_{P V G}$ values at prototypical organic D/A pairs formed between four organic semiconductors [sexithiophene $(6 \mathrm{~T})$, fullerene $\left(\mathrm{C}_{60}\right)$, diindenoperylene (DIP, chemical structure shown in Fig. 1), and poly(3hexylthiophene) (P3HT)] determined using the combination of ultraviolet and inverse photoemission spectroscopy (UPS and IPES). The experiment for $\mathrm{DIP} / \mathrm{C}_{60}$ demonstrates that $E_{P V G}$ can be reliably inferred from measuring the offset between the D/A HOMO levels, once the acceptor's transport gap $\left(E_{t}\right)$ is known and no changes of $E_{t}$ occur upon interface formation. Further UPS experiments for three other D/A interfaces, i.e., 6T/ $\mathrm{C}_{60}, 6 \mathrm{~T} / \mathrm{DIP}$, and $\mathrm{P} 3 \mathrm{HT} / \mathrm{DIP}$, and results from previous work for the $\mathrm{P} 3 \mathrm{HT} / \mathrm{C}_{60}$ interface ${ }^{16}$ yield further $E_{P V G}$ values. These are correlated with the $V_{o c}$ of corresponding planar heterojunction (PHJ) solar cells recently investigated, ${ }^{17,18}$ and a reliable value for $\Delta$ is obtained.

Substrates consisted of thin films of the commercially available conducting polymer poly(ethylene-dioxythiophene):poly(styrenesulfonate) (PEDT:PSS) (Baytron ${ }^{\circledR}$ P AI4083) spin-coated $(1500 \mathrm{rpm})$ on $\mathrm{UV} / \mathrm{O}_{3}$-treated indium tin oxide (ITO) on glass from aqueous dispersion and subsequently annealed at $200^{\circ} \mathrm{C}$ for $5 \mathrm{~min}$ under ambient conditions. The donor polymer P3HT was spin coated (1500 rpm) on top of PEDT:PSS from a chloroform solution $(6 \mathrm{mg} / \mathrm{ml})$ in a $\mathrm{N}_{2}$-filled glove box and annealed at $180^{\circ} \mathrm{C}$ for $30 \mathrm{~min}$. The excess polymer was washed away with the solvent resulting in an insoluble, well defined $3 \mathrm{~nm}$ P3HT layer with electronic properties identical to thicker layers. ${ }^{19}$ The deposition of $\mathrm{C}_{60}$, 6T (Sigma Aldrich), and DIP (S. Hirschmann, Univ. Stuttgart, Germany) from resistivity heated crucibles at deposition rates of approximately $0.1 \mathrm{~nm} / \mathrm{min}$ was done in a preparation chamber (base pressure $<1 \times 10^{-9}$ mbar) with the substrate at room temperature. The nominal film thickness was monitored with a quartz crystal microbalance.

UPS measurements were carried out at the synchrotron light source BESSY II (Berlin) with $35 \mathrm{eV}$ photons and a hemispherical electron analyzer (Scienta SES 100), and in the Humboldt-Universität laboratory using a $\mathrm{He}$ discharge lamp and a Phoibos100 analyzer. In both systems, the secondary electron cutoff (SECO) spectra were measured with a sample bias of $-10 \mathrm{~V}$. The error of energy values from UPS is estimated to be smaller than $50 \mathrm{meV}$. UPS experiments in 


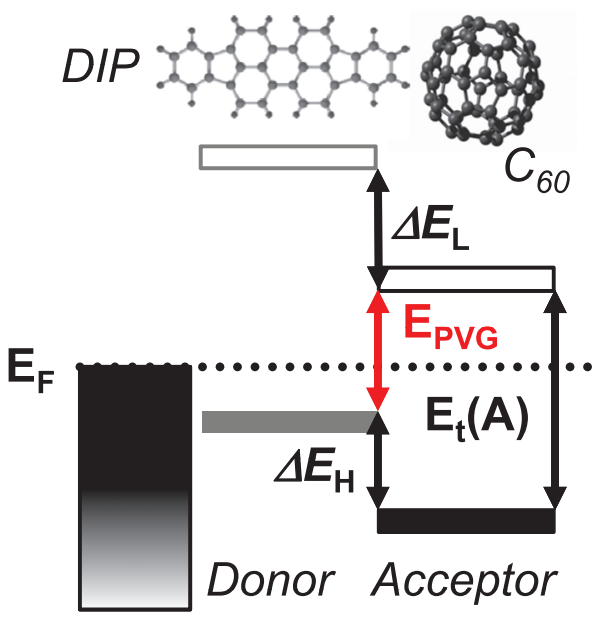

FIG. 1. Scheme of the relevant energy offsets at an organic D/A heterojunction. $\Delta E_{\mathrm{L}}$ denotes the LUMO-LUMO offset, $\Delta E_{\mathrm{H}}$ the HOMO-HOMO offset. The photovoltaic gap is given by $E_{\mathrm{PVG}}=E_{\mathrm{t}}(\mathrm{A})-\Delta E_{\mathrm{H}}$. As example, DIP and $\mathrm{C}_{60}$ are shown as donor and acceptor, respectively.

conjunction with IPES measurements were performed at Princeton University using a similar He discharge source and a double-pass cylindrical mirror analyzer. The resolution of all UPS measurements was $150 \mathrm{meV}$ or slightly better.

IPES was performed in the isochromat mode, using a set-up described elsewhere. ${ }^{20}$ The overall IPES instrumental resolution $(450 \mathrm{meV})$ is estimated from the width of the Fermi step measured on a gold surface. The Gaussian broadening of IPES requires a correction of $50 \mathrm{meV}$ to the onset value of the LUMO and thus to the electron affinity (EA) and the transport gap $\left(E_{t}\right) .^{21}$ The error of energy values from IPES is estimated to be $100 \mathrm{meV}$.

OPVCs ( $4 \mathrm{~mm}^{2}$ area) were fabricated and characterized at Augsburg University. The open circuit voltage $\left(V_{\text {OC }}\right)$ values were extracted from current-voltage characteristics recorded under white LED $\left(54 \mathrm{~mW} / \mathrm{cm}^{2}\right)$ illumination in a $\mathrm{N}_{2}$-filled glove box at room temperature. The effective intensity is estimated to correspond to 1 sun. To account for the deviation from standard illumination conditions, we assume an error of $V_{O C}$ of $\pm 15 \mathrm{mV}$. Temperature variations produce an additional error of $\pm 5 \mathrm{mV}$. Thus, the given $V_{O C}$ values are stated within an error of $\pm 20 \mathrm{mV}$.

Fig. 2 displays the UPS and IPES spectra of $5 \mathrm{~nm}$ $\mathrm{C}_{60} / \mathrm{ITO}$ (bottom), $10 \mathrm{~nm}$ DIP/PEDT:PSS (top), and $1 \mathrm{~nm} \mathrm{C}_{60}$ on $8 \mathrm{~nm}$ DIP/PEDT:PSS (center). All spectra are referenced to the vacuum level $\left(E_{v a c}\right)$ set to zero. The UPS and IPES spectra are left and right of $E_{F}$, respectively. For pristine $\mathrm{C}_{60}$, the HOMO low binding energy (BE) onsets yields an ionization energy (IE) of $6.45 \mathrm{eV}$, the LUMO high $\mathrm{BE}$ onset is at $3.99 \mathrm{eV}$, and thus an onset-onset gap of $2.46 \mathrm{eV}$ is obtained. Taking into account the experimental Gaussian broadening of IPES results in $\mathrm{EA}\left(\mathrm{C}_{60}\right)=3.94 \mathrm{eV}$ and $E_{t}\left(\mathrm{C}_{60}\right)=(2.5 \pm 0.1)$ $\mathrm{eV}$, in good agreement with earlier work. ${ }^{22,23}$ For the pristine DIP film, the onset procedure results in an IE of $5.35 \mathrm{eV}$ (characteristic of standing DIP molecules in the $\mathrm{film}^{18}$ ) and a LUMO high $\mathrm{BE}$ onset of $2.85 \mathrm{eV}$, and hence an onset-onset gap of $2.49 \mathrm{eV}$. Taking into account the experimental IPES broadening leads to $\mathrm{EA}(\mathrm{DIP})=2.80 \mathrm{eV}$ and $E_{t}(\mathrm{DIP})=(2.55$ $\pm 0.1) \mathrm{eV}$. We attribute the slight deviation from an earlier reported value of $2.7 \mathrm{eV}$ to energetic broadening due to higher

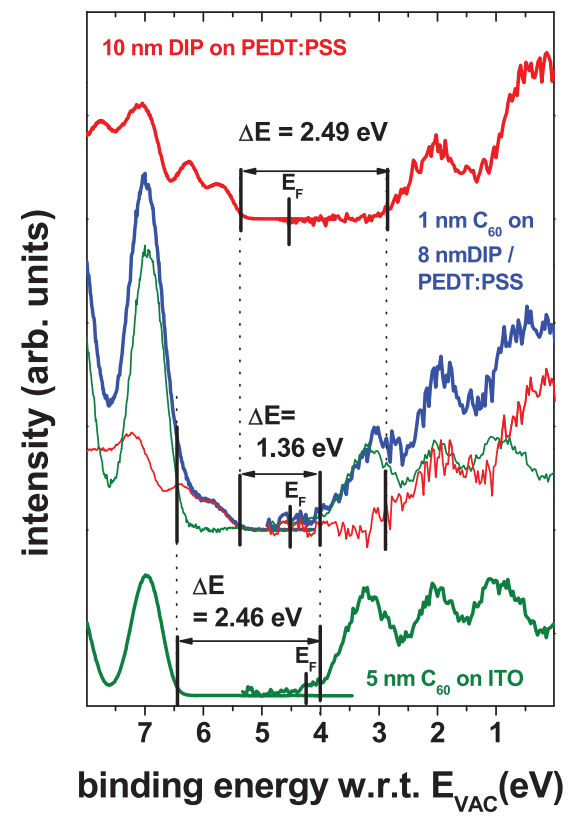

FIG. 2. UPS and IPES spectra of $5 \mathrm{~nm} \mathrm{C}_{60}$ on ITO (bottom), $1 \mathrm{~nm} \mathrm{C}_{60}$ on $10 \mathrm{~nm}$ DIP/PEDT:PSS (center), and $10 \mathrm{~nm}$ DIP on PEDT:PSS (top). Thin lines in die center spectrum are the decomposed contribution of DIP (red) and $\mathrm{C}_{60}$ (green). Depicted vertical ticks and dots are guides for the eye.

disorder in our $10 \mathrm{~nm}$ DIP film on PEDT:PSS compared to a DIP film grown on $\mathrm{Ag}(111) .^{21}$

Turning to heterojunctions, we now use the information acquired above for individual materials to assess whether the transport gaps change upon the D/A interface formation with respect to $E_{t}$ values of the pristine materials. We do so by analyzing the UPS and IPES results from $1 \mathrm{~nm} \mathrm{C}_{60}$ deposited on $8 \mathrm{~nm}$ DIP/PEDT:PSS. Previous thickness-dependent studies of $\mathrm{C}_{60}$ on DIP/PEDT:PSS revealed vacuum level alignment and flat bands in both layers, consistent with a weak interaction between the two materials. ${ }^{18}$

We first discuss the UPS results (left of $E_{F}$ ) of the $\mathrm{DIP} / \mathrm{C}_{60}$ interface. The $\mathrm{C}_{60}$ spectral contribution (thin green line) at the interface was retrieved by subtracting the unshifted and scaled-down neat DIP UPS valence spectrum (thin red line) measured prior to $\mathrm{C}_{60}$ evaporation from the measured interface spectrum (thick blue line). The subtraction procedure yields "clean" $\mathrm{C}_{60}$ features and no energy shifts upon interface formation, and thus the same $\mathrm{C}_{60}$ and DIP IE values as neat films. The energy offset between the two HOMO levels is $1.1 \mathrm{eV}$, in agreement with earlier results. $^{18}$

Turning to the IPES results (right of $E_{F}$ ) from the D/A interface, the broadening-corrected onset of the first measured peak gives an EA of $3.94 \mathrm{eV}$, which is the same value as for a neat $\mathrm{C}_{60}$ film. Thus, we attribute the first IPES peak to the $\mathrm{C}_{60}$ LUMO. The spectral contribution of DIP at the $\mathrm{C}_{60} / \mathrm{DIP}$ interface (thin red line) was retrieved by subtracting the appropriately scaled IPES spectrum of the neat $\mathrm{C}_{60}$ film (thin green line). The subtraction procedure yields "clean" IPES DIP features, and again no energy shifts upon interface formation. Hence, we find the same $\mathrm{C}_{60}$ and DIP EA as in the case of neat $\mathrm{C}_{60}$ and DIP films, and an energy offset between the onsets of the DIP and $\mathrm{C}_{60}$ LUMO levels equal to $1.15 \mathrm{eV}$. Finally, these values yield an onset-onset gap of 


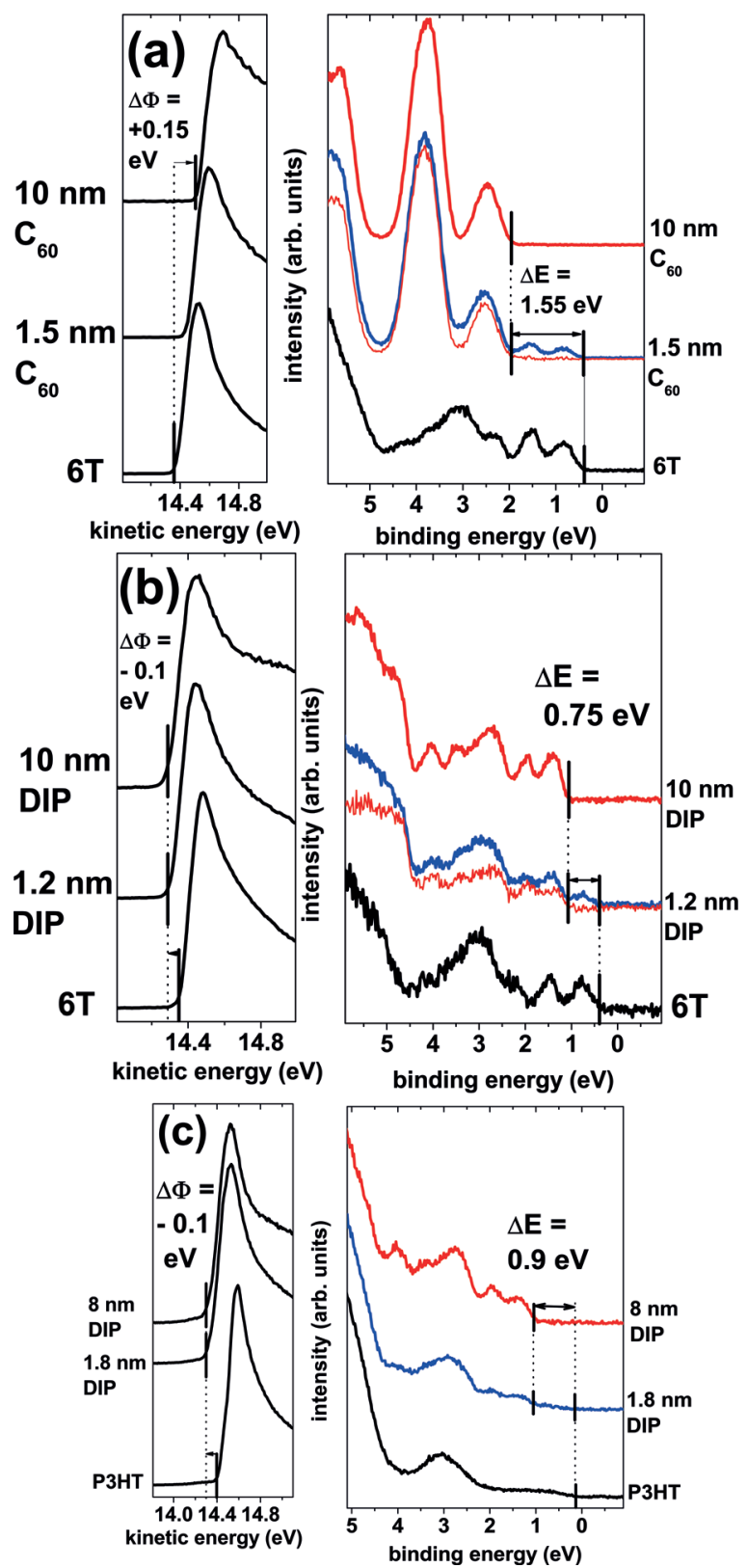

FIG. 3. (a) SECO and valence region photoemission spectra (synchrotron radiation $35 \mathrm{eV})$ for increasing $\mathrm{C}_{60}$ coverage on $6 \mathrm{~T}(10 \mathrm{~nm}) / \mathrm{PEDT}$ :PSS. (b) SECO and valence region photoemission spectra (He II) for increasing DIP coverage on $6 \mathrm{~T}(10 \mathrm{~nm}) / \mathrm{PEDT}: \mathrm{PSS}$. (c) SECO and (b) valence region photoemission spectra (He I) for increasing DIP coverage on P3HT (3 nm)/ PEDT:PSS. Vertical lines and ticks are guides for the eye.

$1.36 \mathrm{eV}$ and a broadening-corrected $E_{P V G}$ of $(1.40 \pm 0.1) \mathrm{eV}$ for the DIP/C 60 interface.

The combined IPES and UPS experiments on the DIP/C 60 interface show that $E_{t}$ of neither compound changes at the weakly interacting organic/organic interface with flat bands on either side of the junction. Note that this result, obtained by careful fitting of the spectra, is in contradiction with the result of another UPS/IPES study of the D/A copper-phthalocyanine $(\mathrm{CuPc}) / \mathrm{C}_{60}$ interface, where significant changes in polarization energy (and thus in $E_{t}$ ) was suggested for the interface compared to the neat materials. ${ }^{15}$ Knowledge of the acceptor $E_{t}$ at the interface now allows the determination of $E_{P V G}$ of other $\mathrm{D} / \mathrm{A}$ interfaces by measurement of the energy separation between the D and A HOMO levels at the heterojunction (illustrated in Fig. 1), which we present below.

The UPS results obtained for the $\mathrm{C}_{60}$ and DIP grown on $10 \mathrm{~nm}$ thick donor 6T layers (on PEDT:PSS) are displayed in Figs. 3(a) and 3(b), respectively. Note that in conjunction with 6T, both $\mathrm{C}_{60}$ and DIP take the role of the acceptor. The evolution of the SECO upon deposition of $\mathrm{C}_{60}$ on 6T/PEDT:PSS is shown in the left panel of Fig. 3(a). The initial work function of $4.35 \mathrm{eV}$ increases to $4.5 \mathrm{eV}$ upon deposition of $10 \mathrm{~nm} \mathrm{C}_{60}$. The small interface dipole of $+0.15 \mathrm{eV}$ is most likely due to minute intermolecular charge transfer and/or mutual polarization of molecules at the interface, in analogy to the case of similar heterojunctions. ${ }^{24-26}$ Note, however, that a clear-cut identification of the origin of the interface dipole at the molecular scale would only be possible with extensive theoretical modeling, which is beyond the scope of this work.

The low BE onset of the 6T HOMO peak is observed $0.35 \mathrm{eV}$ below $\mathrm{E}_{\mathrm{F}}$ in the valence region shown in the right panel of Fig. 3(a). This yields an IE of $4.7 \mathrm{eV}$ for the $10 \mathrm{~nm}$ thick 6T layer on PEDT:PSS, which corresponds well with previous reports on layers of upright-standing $6 \mathrm{~T}$ molecules. ${ }^{27}$ As long as the $6 \mathrm{~T}$ levels are still detectable upon increasing $\mathrm{C}_{60}$ coverage, their $\mathrm{BE}$ remains unchanged. Applying the subtraction procedure described above to the $1.5 \mathrm{~nm} \mathrm{C} \mathrm{C}_{60} / \mathrm{DIP}$ spectrum yields a "clean" $\mathrm{C}_{60}$ spectrum [thin line in the right panel of Fig. 3(b)] with a low BE HOMO onset at $1.9 \mathrm{eV}$, which is the same as for larger thicknesses. Consequently, flat band conditions prevail also at the $\mathrm{C}_{60} / 6 \mathrm{~T}$ interface. The energy offset between the low BE onsets of the $\mathrm{C}_{60}$ and 6T HOMO levels is $1.55 \mathrm{eV}$.

The evolution of the SECO upon deposition of DIP on 6T/PEDT:PSS is shown in the left panel of Fig. 3(b). The initial 6T/PEDT:PSS work function of $4.35 \mathrm{eV}$ is slightly decreased to $4.25 \mathrm{eV}$ upon deposition of $1.2 \mathrm{~nm}$ DIP and remains constant for higher DIP coverage. The small interface dipole of $-0.1 \mathrm{eV}$ is tentatively attributed to mutual polarization. The thickness-dependent valence spectra of DIP grown on 6T/PEDT:PSS are shown in the right panel of Fig. 3(b). As before, the low BE onset of the 6T HOMO is at $0.35 \mathrm{eV}$ BE. The subtraction procedure reveals the low $\mathrm{BE}$ onset of the DIP HOMO emission at $1.1 \mathrm{eV}$ BE [thin line in

TABLE I. HOMO offsets $\Delta E(\mathrm{HOMO}), E_{P V G}$, and open circuit voltages (Voc) measured under same illumination conditions at room temperature of investigated D/A interfaces. The transport gap $\left(E_{t}\right)$ of $\mathrm{C}_{60}$ is $2.50 \mathrm{eV}$ and of DIP it is $2.55 \mathrm{eV}$.

\begin{tabular}{|c|c|c|c|c|}
\hline D/A pair & $\Delta E(\mathrm{HOMO})(\mathrm{eV})$ & $E_{P V G}(\mathrm{eV})$ & $\operatorname{Voc}(\mathrm{V})$ & $\Delta(\mathrm{eV})$ \\
\hline $\mathrm{DIP} / \mathrm{C}_{60}$ & $1.10 \pm 0.05$ & $1.40 \pm 0.15$ & $0.93 \pm 0.02$ & 0.47 \\
\hline $6 \mathrm{~T} / \mathrm{C}_{60}$ & $1.55 \pm 0.05$ & $0.95 \pm 0.15$ & $0.45 \pm 0.02$ & 0.50 \\
\hline $\mathrm{P} 3 \mathrm{HT} / \mathrm{C}_{60}$ & $1.50 \pm 0.05$ & $1.00 \pm 0.15$ & $0.50 \pm 0.02$ & 0.50 \\
\hline 6T/DIP & $0.75 \pm 0.05$ & $1.80 \pm 0.15$ & $1.38 \pm 0.02$ & 0.42 \\
\hline P3HT/DIP & $0.90 \pm 0.05$ & $1.65 \pm 0.15$ & $1.24 \pm 0.02$ & 0.41 \\
\hline
\end{tabular}




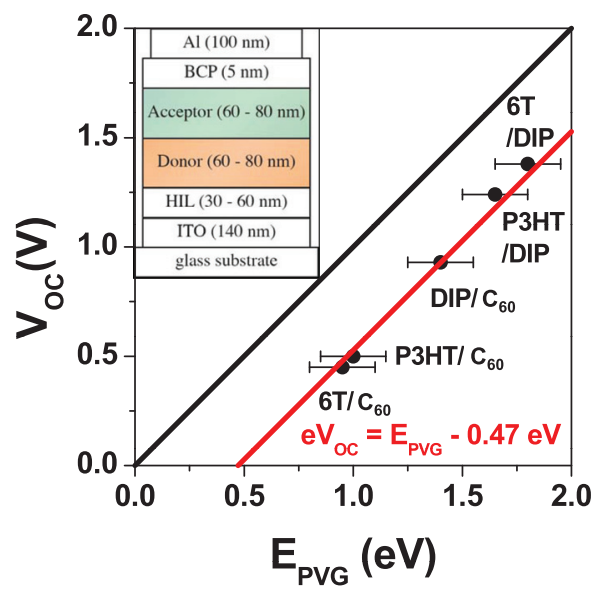

FIG. 4. $V_{O C}$ versus $E_{P V G}$ of planar heterojunction OPVCs with a device structure as shown in the inset.

Fig. 3(b)]. As the layer thickness is increased, no energy shift is detected in the valence region, indicating flat levels in both the DIP and 6T layers. The IE of the DIP layer is $5.35 \mathrm{eV}$, which corresponds to that of a layer of standing DIP molecules. ${ }^{18}$ The energy offset between the low BE emission onsets from the 6T and DIP HOMO levels is $0.75 \mathrm{eV}$, which is only about half of what was found for $6 \mathrm{~T} / \mathrm{C}_{60}$.

The interface results for DIP grown on P3HT/PEDT:PSS [Fig. 3(c)] were analyzed in the same way as the previously described interfaces. The experimental results of the D/A HOMO level offsets of DIP and $\mathrm{C}_{60}$ on P3HT/PEDT:PSS are given in Table I.

The energy level offsets of the five investigated heterojunctions and the $V_{\mathrm{OC}}$ values obtained from the corresponding solar cells are summarized in Table I. In a $E_{\mathrm{PVG}}$ Vs. $V_{\mathrm{OC}}$ plot (Fig. 4), covering an $E_{\mathrm{PVG}}$ range from $0.95 \mathrm{eV}$ to $1.80 \mathrm{eV}$, we find the predicted linear relationship between $V_{\mathrm{OC}}$ and $E_{P V G}$ with a slope of unity and an intersection with the energy axis at $(0.47 \pm 0.05) \mathrm{eV}$, indicating that for all five OPVCs, the $V_{O C}$ at room temperature is about half a Volt smaller than the HOMO-LUMO energy level offset at the respective D/A interface, i.e., the loss $\Delta$ discussed in the Introduction. From the obtained relationship between $V_{\mathrm{OC}}$ and $E_{\mathrm{PVG}}$, we conclude that a minimum photovoltaic gap of ca $0.5 \mathrm{eV}$ is required in order to obtain a photovoltaic response for planar heterojunction OPVCs at room temperature. Noteworthy, all investigated interfaces exhibit a very similar value of $\Delta$, despite the rather different nature of the two acceptors (DIP vs. $\mathrm{C}_{60}$ ) and the molecular material 6T vs. the polymer P3HT.

In conclusion, we found the same transport gaps for DIP $(2.55 \mathrm{eV})$ and $\mathrm{C}_{60}(2.50 \mathrm{eV})$ at the $\mathrm{C}_{60} / \mathrm{DIP}$ interface as for the pristine $\mathrm{C}_{60}$ and DIP layers. Furthermore, small but finite interface dipoles and flat energy levels were measured for the organic D/A heterojunctions $6 \mathrm{~T} / \mathrm{C}_{60}, 6 \mathrm{~T} / \mathrm{DIP}$, and P3HT/ $\mathrm{DIP}$, but none for $\mathrm{DIP} / \mathrm{C}_{60}$. Comparing the photovoltaic gap of each interface, and in addition also that of $\mathrm{P} 3 \mathrm{HT} / \mathrm{C}_{60}$, with the open circuit voltage measured on corresponding OPVCs, we find that a minimum $E_{P V G}$ of approximately $0.5 \mathrm{eV}$ is necessary for a photovoltaic response of these heterojunctions at room temperature under illumination intensities around 1 sun. The fact that the reliably determined $\Delta$ values for vastly dissimilar material pairs are very similar is remar- kable in the light of the various discussed origins of this energy loss. For instance, it should be important to identify radiative and non-radiative recombination loss mechanisms ${ }^{5}$ at the D/A interfaces and to investigate possible counteracting trends of their ratio.

The authors thank S. Krause for valuable discussion and S. Olthof and A. Dai for experimental support. We thank A. Elschner (Heraeus Clevios $\mathrm{GmbH}$ ) for providing PEDT:PSS and J. P. Rabe (HU-Berlin) for granting access to UPS. This work was financially supported by Deutsche Forschungsgemeinschaft (DFG) through SPP1355 and SFB951, the National Science Foundation (NSF) (Grant No. DMR1005892), and the Princeton MRSEC of the NSF (Grant No. DMR-0819860). U.H. gratefully acknowledges the Bavarian Research Foundation for financial support.

${ }^{1}$ L. J. A. Koster, V. D. Mihailetchi, R. Ramaker, and P. W. M. Blom, Appl. Phys. Lett. 86, 123509 (2005).

${ }^{2}$ B. P. Rand, D. P. Burk, and S. R. Forrest, Phys. Rev. B 75, 115327 (2007).

${ }^{3}$ M. Riede, T. Mueller, W. Tress, R. Schueppel, and K. Leo, Nanotechnology 19, 424001 (2008).

${ }^{4}$ G. Dennler, M. C. Scharber, and C. J. Brabec, Adv. Mater. 21, 1323 (2009).

${ }^{5}$ M. Gruber, J. Wagner, K. Klein, U. Hörmann, A. Opitz, M. Stutzmann, and W. Brütting, Adv. Energy Mater. 2, 1100 (2012).

${ }^{6}$ D. Veldman, S. C. J. Meskers, and R. A. J. Janssen, Adv. Funct. Mater. 19, 1939 (2009).

${ }^{7}$ K. Vandewal, K. Tvingstedt, A. Gadisa, O. Inganäs, and J. V. Manca, Phys. Rev. B 81, 125204 (2010).

${ }^{8}$ A. Rajagopal, C. I. Wu, and A. Kahn, J. Appl. Phys. 83, 2649 (1998).

${ }^{9}$ H. Ishii, K. Sugiyama, W. Ito, and K. Seki, Adv. Mater. 11, 605 (1999).

${ }^{10}$ H. Vazquez, W. Gao, F. Flores, and A. Kahn, Phys. Rev. B 71, 041306R (2005).

${ }^{11}$ M. Linares, D. Beljonne, J. Cornil, K. Lancaster, J. L. Brédas, S. Verlaak, A. Mityashin, P. Heremans, A. Fuchs, C. Lennartz, J. Idé, R. Méreau, P. Aurel, L. Ducasse, and F. Castet, J. Phys. Chem. C 114, 3215 (2010).

${ }^{12}$ K. Akaike, A. Opitz, J. Wagner, W. Brütting, K. Kanai, Y. Ouchi, and K. Seki, Org. Electron. 11, 1853 (2010).

${ }^{13}$ Z.-L. Guan, J. B. Kim, Y.-L. Loo, and A. Kahn, J. Appl. Phys. 110, 043719 (2011).

${ }^{14}$ E. L. Ratcliff, J. Meyer, K. X. Steirer, N. R. Armstrong, D. Olson, and A. Kahn, Org. Electron. 13, 744 (2012).

${ }^{15}$ K. Akaike, K. Kanai, Y. Ouchi, and K. Seki, Adv. Funct. Mater. 20, 715 (2010).

${ }^{16}$ F. J. Zhang, A. Vollmer, J. Zhang, Z. Xu, J. P. Rabe, and N. Koch, Org. Electron. 8, 606 (2007).

${ }^{17}$ U. Hörmann, J. Wagner, M. Gruber, A. Opitz, and W. Brütting, Phys. Status Solidi (RRL) 5, 241 (2011).

${ }^{18}$ J. Wagner, M. Gruber, A. Hinderhofer, A. Wilke, J. Frisch, P. Amsalem, B. Broeker, A. Vollmer, A. Opitz, N. Koch, F. Schreiber, and W. Bruetting, Adv. Funct. Mater. 20, 4295 (2010).

${ }^{19}$ J. Frisch, A. Vollmer, J. P. Rabe, and N. Koch, Org. Electron. 12, 916 (2011).

${ }^{20}$ C. I. Wu, Y. Hirose, H. Sirringhaus, and A. Kahn, Chem. Phys. Lett. 272, 43 (1997).

${ }^{21}$ S. Krause, M. Casu, A. Schöll, and E. Umbach, New J. Phys. 10, 085001 (2008); S. Krause, doctoral thesis (University Würzburg, 2009), http://opus. bibliothek.uni-wuerzburg.de/volltexte/2009/4047/pdf/Diss_S_Krause.pdf.

${ }^{22}$ J. H. Weaver, J. Phys. Chem. Solids 53, 1433 (1992).

${ }^{23}$ R. W. Lof, M. A. van Veenendaal, B. Koopmans, H. T. Jonkman, and G. A. Sawatzky, Phys. Rev. Lett. 68, 3924 (1992).

${ }^{24}$ S. Verlaak, D. Beljonne, D. Cheyns, C. Rolin, M. Linares, F. Castet, J. Cornil, and P. Heremans, Adv. Funct. Mater. 19, 1 (2009).

${ }^{25}$ F. Rissner, G. M. Rangger, O. T. Hofmann, A. M. Track, G. Heimel, and E. Zojer, ACS Nano 3, 3513 (2009).

${ }^{26}$ A. Wilke, P. Amsalem, J. Frisch, B. Bröker, A. Vollmer, and N. Koch, Appl. Phys. Lett. 98, 123304 (2011).

${ }^{27}$ S. Duhm, G. Heimel, I. Salzmann, H. Glowatzki, R. L. Johnson, A. Vollmer, J. P. Rabe, and N. Koch, Nature Mater. 7, 326 (2008). 